\title{
Evaluation of Potential Factors Predicting Attainment of Full Gavage Feedings in Preterm Infants
}

\author{
Robert J. Shulman ${ }^{\mathrm{a}}$ Ching-Nan Ou ${ }^{\mathrm{b}}$ E. O'Brian Smith ${ }^{\mathrm{a}}$

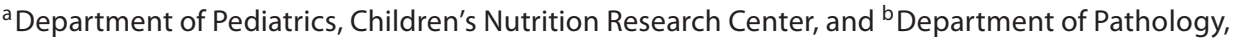 \\ Baylor College of Medicine, Texas Children's Hospital, Houston, Tex., USA
}

\section{Key Words}

Feeding, premature/preterm infant $\cdot$ Lactase $\cdot$ Permeability, gastrointestinal $\cdot$ Gavage feeding $\cdot$ Gastric residual volume . Abdominal distention

\begin{abstract}
Background: The clinical measures of gastric residuals and abdominal distention are often used to guide feeding in preterm infants, but there are few data demonstrating their usefulness. Similarly, techniques are now available to investigate gastrointestinal (Gl) function noninvasively and safely, but their ability to predict attainment of full gavage feedings and/or feeding volume in preterm infants is unclear. Objective: We sought to determine prospectively the potential relationships of attainment of full gavage feedings and feeding volume with clinical measures and noninvasive Gl tests. Methods: Fifty preterm infants were followed prospectively. Daily tally was taken of gavage feeding intake, gastric residual volumes (GRVs; milliliters per day, number of GRVs $>50 \%$ of the previous feeding volume, and number of GRVs $>2 \mathrm{ml} /$ $\mathrm{kg})$, and abdominal distention. Infants underwent repeated measurement of lactase activity, GI permeability, fecal calprotectin concentration, and gastric emptying. Results: The number of GRVs $>2 \mathrm{ml} / \mathrm{kg}$ tended to decrease with postnatal
\end{abstract}

age $(p=0.06)$. Lactase activity and feeding volume in milliliters per kilogram per day prior to achieving full feedings were correlated $(p=0.007, \beta=0.164)$. There was no correlation between feeding outcomes and GRV (ml/day), GRV $>50 \%, \mathrm{GRV}>2 \mathrm{ml} / \mathrm{kg}$, small bowel, colonic, or whole bowel permeability, fecal calprotectin concentration, gastric emptying, or abdominal distention. Conclusions: GRV is unreliable in predicting attainment of full gavage feeding. Lactase activity is related to feeding volume. However, other noninvasive GI tests utilized were not predictive. These data cast doubt upon the utility of GRV in guiding feeding therapy. Randomized trials of different GRV management protocols are needed.

Copyright $\odot 2010$ S. Karger AG, Basel

\section{Introduction}

Gastrointestinal (GI) function in the preterm infant is underdeveloped compared with that in the term infant. Consequently, preterm infants experience presumed symptoms of feeding intolerance such as increased gastric residuals after feeding and abdominal distention that delay the attainment of full gavage feedings [1].

Robert J. Shulman, MD

Department of Pediatrics, Children's Nutrition Research Center

1100 Bates Ave.

Houston, TX 77030-2600 (USA)

E-Mail karger@karger.ch_Accessible online at:

www.karger.com www.karger.com/neo
Tel. +1 713798 7178, Fax +1 713798 7187, E-Mail rshulman@bcm.tmc.edu 
Clinically, measurement of gastric residuals is often used as a guide to advance feedings in the preterm infant, but there are few data demonstrating its usefulness $[2,3]$. It is likely that increased gastric residuals are not only a result of poor gastric emptying, but reflect motor immaturity in the small intestine and perhaps colon $[3,4]$. In addition, other factors related to GI development, such as lactase activity, may also influence the ability to attain full gavage feedings [5].

Techniques are now available to investigate GI function noninvasively and safely in preterm infants. These include the ability to measure lactase activity, GI permeability, GI inflammation, and gastric emptying [5-11]. These tests potentially offer an objective measure of GI function that may correlate with GI maturation and, thus, predict the ability of preterm infants to achieve full gavage feedings. However, the usefulness of these tests is unclear.

The objectives of this study were to determine prospectively the potential relationships between the attainment of full gavage feedings and clinical measures including gastric residual volume (GRV) and abdominal distention. In addition, we carried out noninvasive GI tests (lactase activity, GI permeability, fecal calprotectin concentration, gastric emptying) to determine if there is a relationship with feeding volume and the attainment of full gavage feedings.

\section{Materials and Methods}

Preterm infants (25-32 weeks gestational age) were followed prospectively. After permission from the attending neonatologist, the parents were approached for consent. All procedures were approved by the Baylor College of Medicine Institutional Review Board. We attempted to enroll infants as soon as possible after birth. Infants with major congenital anomalies and/or known GI abnormalities were not enrolled. Permission to carry out measurements was obtained from the attending neonatologist prior to each procedure.

\section{Feeding Management}

Feedings were begun by orogastric tube as soon as the infants were clinically stable, generally by 4 days of age. Feedings were given by gavage over 20 min every $3 \mathrm{~h}$ starting at $20 \mathrm{ml} / \mathrm{kg} /$ day with the infant in the supine position. It was attempted to advance feedings by $20 \mathrm{ml} / \mathrm{kg} /$ day until the infants achieved full gavage feedings (i.e. $100 \%$ of their nutrient requirements by gavage) as we have described previously [12]. The infant's clinical chart was reviewed daily for feeding history. Feeding intolerance and its management were guided according to a previously published algorithm and our previous clinical trial $[12,13]$. In brief, an increased GRV, abnormal abdominal examination (see below), or hematochezia prompted a complete physical examination including as- sessment of gastric tube placement, and if deemed appropriate, an abdominal radiograph. Depending on the severity of the findings, feedings were either reduced by $20 \%$ or withheld. Serial evaluations were done to decide on further management (e.g. glycerin suppository if stooling frequency was $<1$ stool/36 h, change of body position, further reduction in feeding volume or continued withholding of feedings) $[12,13]$.

\section{Feeding Outcomes}

The feeding outcomes were defined as: on full gavage feedings or not; feeding volume in milliliters per kilogram per day, feeding volume in milliliters per kilogram per day prior to the time full gavage feedings were achieved, and time to full gavage feedings. Full gavage feedings were defined as the infant achieving appropriate weight gain $(\sim 15 \mathrm{~g} / \mathrm{kg} /$ day) solely via gavage feedings (i.e. without the need for parenteral nutrition), which usually occurred when the infants were receiving $120 \mathrm{kcal} / \mathrm{kg} / \mathrm{day}(150 \mathrm{ml} /$ $\mathrm{kg} /$ day). Time to full gavage feedings was defined both as the postnatal age at which full gavage feedings were achieved as well as the total number of days the infants were fed until they achieved full gavage feeding. If the infant reached full gavage feedings but the feedings were subsequently reduced, the day the infant first achieved full gavage feedings was used.

\section{Clinical Measures of Feeding Tolerance}

Feeding tolerance was assessed daily starting on the first day that feedings were attempted. The following characteristics were noted: GRV, vomiting, abdominal distention (increase in abdominal girth $>1.5 \mathrm{~cm}$ ), number of feedings held, and green or bloodtinged gastric aspirates $[4,12,14,15]$. Data were obtained daily from the infant's clinical chart.

\section{Gastric Residual Volume}

GRV was determined by gentle aspiration of gastric contents from the indwelling orogastric tube every $3 \mathrm{~h}$ prior to the next feeding. The total number of gastric residuals was noted as well as the number of GRV that was $>50 \%$ of the previous feeding volume and $>2 \mathrm{ml} / \mathrm{kg}$ body weight as has been used and recommended previously $[12,13]$. These parameters have been shown previously in preterm infants to segregate tolerance to different feeding regimens [12]. GRV was expressed as the mean milliliters per day, mean milliliters per kilogram per day, mean number per day of GRVs $>50 \%$ of the previous feeding, and mean number per day of GRVs $>2 \mathrm{ml} / \mathrm{kg}$.

\section{Lactase Activity and GI Permeability}

Lactase activity and GI bowel permeability were determined as described previously $[5,8,16]$. In brief, every 2 weeks the infants were administered a solution containing the sugars lactulose, mannitol, and sucralose at concentrations of $60 \mathrm{mg} / \mathrm{ml}(167$ $\mathrm{mmol} / \mathrm{l}), 12 \mathrm{mg} / \mathrm{ml}(66.7 \mathrm{mmol} / \mathrm{l})$, and $60 \mathrm{mg} / \mathrm{ml}(167 \mathrm{mmol} / \mathrm{l})$, respectively, at a dose of $0.25 \mathrm{ml} / \mathrm{kg}$ per feeding. The solution was administered in each feeding for $36 \mathrm{~h}$ [7]. The lactose in the feeding provided the lactose for the study (approximately $3.5 \mathrm{~g} / \mathrm{dl} ; 97$ $\mathrm{mmol} / \mathrm{l}$ ). During the final $6 \mathrm{~h}$, urine was collected using a urine collection bag. Because very small amounts of lactulose and mannitol may normally be present in feedings and/or medications, ratios involving these two sugars were expressed as the ratio in the urine versus that in the milk $[5,8]$. 
Urinary lactulose/lactose has been shown to correlate closely with enzymatically determined lactase activity in the small intestinal mucosa [17]. The lactulose/mannitol ratio, sucralose/lactulose ratio, and sucralose percent recovery reflect small bowel, colonic, and total bowel permeability, respectively [18, 19]. Urine was analyzed as we have described previously [16].

\section{Fecal Calprotectin Concentration}

A random stool sample was collected weekly to determine the fecal calprotectin concentration as a measure of GI inflammation $[9,20]$. Stool was analyzed as previously reported using a commercially available ELISA technique (Genova Diagnostics, Asheville, N.C., USA) $[9,20]$.

\section{Gastric Emptying}

Gastric emptying was determined every 2 weeks using the ${ }^{13} \mathrm{C}$ octanoic acid breath test as described previously [10, 11, 21]. The half emptying time (time required to empty half the stomach contents) and the gastric emptying coefficient (rate of gastric emptying per unit time unique to the breath test) were calculated [21,22].

\section{Data Analysis}

Each day it was noted whether the infant was on full gavage feedings or not. The feeding volume $(\mathrm{ml} / \mathrm{kg} / \mathrm{day})$ each day was calculated (including the time on full gavage feedings). We also determined the feeding volumes $(\mathrm{ml} / \mathrm{kg} /$ day) prior to the time the infant achieved full gavage feedings. Both the postnatal age at which full gavage feedings were reached and the number of days of feeding prior to the attainment of full gavage feedings were noted. These measures were used as outcomes.

The generalized estimating equations (GEE) technique provided in SPSS 17.0 was used to assess the effect of GRV, abdominal distention, lactase activity, GI permeability, fecal calprotectin concentration, and gastric emptying on the feeding outcomes. GEE is a multivariable method that accounts for potential confounders in determining how predictor variables are associated with the dependent variable(s). GEE accounts for correlation between repeated measures obtained over time on each subject and allows control of time-dependent covariates such as postnatal age, type of feeding (e.g. formula), and weight. The method assumed the Poisson, binomial, normal or gamma distribution for outcomes that were counts, dichotomies, continuous normal or continuous right skewed, respectively. The within subject correlation structure was assumed to be AR(1) which is appropriate for longitudinal data. Mean values for each infant were calculated and then used to calculate group means. The sample size in this study $(\mathrm{n}=50)$ was sufficient to detect a correlation of 0.4 or greater between feeding outcomes and predictors with a type I error of 0.05 and power of 0.80 . We presumed that correlations of $<0.4$ were not clinically important. Data are expressed as mean $\pm \mathrm{SD}$.

\section{Results}

A total of 50 infants were enrolled in the study. Mean birth weight was $1,200 \pm 330 \mathrm{~g}$, and mean gestational age at birth was $28.6 \pm 2.2$ weeks. Full feedings were achieved at $21.0 \pm 12.8$ (range 7-63) days of age and after $16.5 \pm$
10.9 (range 6-53) days of feeding. Eight infants received human milk and human milk fortifier, 27 human milk, human milk fortifier, and formula, 10 formula alone, and 5 human milk and formula. Mean weight gain was 23.0 $\pm 6.3 \mathrm{~g} /$ day, and mean linear growth was $0.13 \pm 0.09 \mathrm{~cm} /$ day (from birth until time of discharge).

For each infant, the mean GRV prior to full gavage feedings being achieved was $5.3 \pm 3.3$ (range 0.0-12.4) $\mathrm{ml} /$ day or $3.3 \pm 2.1$ (range $0.4-9.5$ ) $\mathrm{ml} / \mathrm{kg} /$ day. For each infant, the mean number per day of GRVs $>50 \%$ of the previous feeding prior to full gavage feedings being achieved was $0.05 \pm 0.12$ (range $0.00-0.72$ ) and the mean number per day of GRVs $>2 \mathrm{ml} / \mathrm{kg}$ /day prior to full gavage feedings being achieved was $0.3 \pm 0.3$ (range $0.0-$ 1.6). No residuals were green-colored. The mean number of days with abdominal distention prior to full gavage feedings being achieved was $0.03 \pm 0.07$ (range $0.00-$ 0.30 ). The mean number of emeses per day prior to full gavage feedings being achieved was $0.3 \pm 0.4$ (range $0.0-$ 2.0 ). The mean number of stools per day prior to full gavage feedings being achieved was $2.5 \pm 1.0$ (range 0.65.1). One infant had confirmed necrotizing enterocolitis. A total of 46/50 infants received continuous positive airway pressure (CPAP). The mean and median duration of CPAP therapy was 15.8 and 7 days, respectively. Thus, the vast majority of infants were not on CPAP therapy at the time the GI tests were done.

The results of lactase activity, GI permeability, fecal calprotectin concentration, and gastric emptying measurements are shown in table 1 . Although we attempted to repeat the measurements regularly as described in the Methods, neonatologists' permission dictated that this could not be accomplished with the desired frequency. Although more than 4 studies were carried out, the number of infants who had more than this number was small. As a result, we did not have confidence in the mean values obtained beyond the fourth study. Consequently, we only used the data from the first four studies (table 1). For the lactase and permeability studies, 3 of the 110 values for each study were $>3 \mathrm{SD}$ of the mean, so these values were excluded.

The number of GRVs $>2 \mathrm{ml} / \mathrm{kg}$ tended to decrease with postnatal age $(\mathrm{p}=0.06, \beta=-0.012,95 \%)$. There was no change with postnatal age in GRV $>50 \%$ or GRV. There was no change with postnatal age in the number of days with abdominal distention or in the number of stools per day. There was no change with postnatal age in lactase activity, GI permeability, fecal calprotectin concentration, or gastric emptying (half emptying time or gastric emptying coefficient). 
Table 1. Measurements

\begin{tabular}{|c|c|c|c|c|}
\hline & Study 1 & Study 2 & Study 3 & Study 4 \\
\hline Postnatal age, days ${ }^{1}$ & $28 \pm 13$ & $44 \pm 14$ & $62 \pm 16$ & $74 \pm 25$ \\
\hline Number of infants & 42 & 33 & 22 & 7 \\
\hline Lactulose/lactose $^{2}$ & $8.6 \pm 13.2$ & $4.7 \pm 12.9$ & $2.0 \pm 2.1$ & $2.4 \pm 1.0$ \\
\hline Lactulose/mannitol ${ }^{2}$ & $0.077 \pm 0.130$ & $0.145 \pm 0.194$ & $0.133 \pm 0.191$ & $0.067 \pm 0.071$ \\
\hline Sucralose/lactulose ${ }^{2}$ & $22.7 \pm 35.5$ & $16.3 \pm 27.6$ & $14.4 \pm 18.1$ & $6.1 \pm 6.8$ \\
\hline Sucralose, mg over $6 \mathrm{~h}$ & $3.4 \pm 3.1$ & $3.4 \pm 2.3$ & $3.2 \pm 3.1$ & $2.9 \pm 2.5$ \\
\hline Postnatal age, days ${ }^{1}$ & $29 \pm 14$ & $36 \pm 14$ & $48 \pm 14$ & $54 \pm 15$ \\
\hline Number of infants & 46 & 25 & 13 & 7 \\
\hline Calprotectin, $\mu \mathrm{g} / \mathrm{g}$ & $266 \pm 14$ & $368 \pm 283$ & $311 \pm 224$ & $273 \pm 245$ \\
\hline Postnatal age, days ${ }^{1}$ & $28 \pm 16$ & $44 \pm 20$ & $67 \pm 15$ & \\
\hline Number of infants & 38 & 30 & 9 & \\
\hline Half emptying time, min & $136 \pm 72$ & $186 \pm 301$ & $130 \pm 30$ & ND \\
\hline Gastric emptying coefficient & $3.6 \pm 0.7$ & $3.4 \pm 0.7$ & $3.4 \pm 0.4$ & ND \\
\hline \multicolumn{5}{|c|}{$\begin{array}{l}\text { Unless otherwise indicated, the values are mean } \pm \mathrm{SD} . \mathrm{ND}=\text { Not done. } \\
{ }^{1} \text { Refers to postnatal age when the studies were carried out. } \\
{ }^{2} \text { Expressed as the ratio of urine to milk. }\end{array}$} \\
\hline
\end{tabular}

The feeding outcomes (on full feedings or not, feeding volume in milliliters per kilogram per day, feeding volume in milliliters per kilogram per day prior to the time of full gavage feedings, and time to full gavage feedings) were compared with the GRV and the GI tests. There was a significant relationship between lactase activity and the feeding volume in milliliters per kilogram per day prior to the time full feedings were achieved ( $\mathrm{p}=0.007, \beta=$ 0.164 ). There was no correlation detected between the feeding outcomes and GRV (ml/day), GRV $>50 \%$, GRV $>2 \mathrm{ml} / \mathrm{kg}$, small bowel, colonic, or whole bowel permeability, fecal calprotectin concentration, gastric emptying (half emptying time or gastric emptying coefficient), or abdominal distention (even when accounting for CPAP treatment). Adding the covariates postnatal age, gestational age at birth, gestational age at the time of study, age when feedings started, or weight did not influence the results to any significant degree.

\section{Discussion}

Although a number of clinical observations (e.g. gastric residuals, abdominal distention) have been used to guide feeding advancement, most are based on consensus or local belief, and there are few data upon which to assess their usefulness [3]. Our prospective data suggest that there are few factors which are predictive of the attainment of full gavage feedings in preterm infants.

Gastric residuals and abdominal distention are used most often to guide feeding therapy because of the belief that a certain amount of GRV and/or distention reflects feeding intolerance [1]. However, except for the extreme case when the stomach is not emptying due to obstruction or gastroparesis, the relationship between GRV and an inability to tolerate gavage feedings has been stated to be unclear [3]. In a previous randomized trial of bolus versus continuous feeding in preterm infants we demonstrated that neither increased GRV nor abdominal distention was associated with a delay in attaining full gavage feedings [12]. However, the different feeding methods used in that study may somewhat cloud that interpretation [12]. In the current study, all infants were fed by gavage. In the current study, the three methods of assessing GRV ( $\mathrm{ml} /$ day, $>50 \%$ of the volume of the preceding feeding, $>2 \mathrm{ml} / \mathrm{kg}$ ) bore no relationship with the gavage feeding outcomes. Similarly, abdominal distention had no predictive value for feeding outcome, even when accounting for the use of CPAP which may induce abdominal distention. Mihatsch et al. [2] retrospectively evaluated their data from a large feeding trial to determine the factors that predicted feeding volume at 14 days of age. They observed that feeding volume was inversely related to the number of GRV that was $0 \mathrm{ml}$ in volume or 
milky [2]. However, no data were provided as to whether there was a relationship with feeding volume or when full gavage feedings were achieved [2]. Particularly for preterm infants, use of GRV to determine feeding advancement may be a 'self-fulfilling prophecy'. By arbitrarily setting a GRV to guide feeding, the time to full gavage feeding in some cases may be predetermined.

Data on GRV in adult studies show that GRV does not correlate well with clinical outcome, and aggressive use of GRVs may cause unwarranted delays in feeding advancement [23]. Further, GRV is very dependent on patient position, tube placement, and type and size of feeding tube used [23].

To potentially obviate the influence of arbitrary standards on feeding advancement, we also sought to determine if there was a relationship between the feeding outcomes and possibly more objective measures of GI function/state. Consequently, we compared the feeding outcomes with GI tests.

Lactase activity increases fourfold in the last trimester [24]. We have previously shown that lactase activity also increases postnatally in preterm infants $[5,25]$. It is unclear why we did not observe a relationship with postnatal age in the current study (table 1). However, the infants in the present study were older than those in our previous studies, and it is possible that we missed the period when the increase is the greatest $[5,25]$.

Other investigators have shown that reducing the lactose intake decreases the risk of feeding intolerance and can enhance weight gain in preterm infants $[26,27]$. Indeed, in our current study, there was a positive relationship between lactase activity and the feeding volume in milliliters per kilogram per day prior to the time full gavage feedings were achieved. That is, the greater the lactase activity, the greater the volume of feeding that could be given. Whether this relationship is related to inherently greater lactase activity in some infants and/or stimulation of lactase by feeding requires further studies. Data suggest that both mechanisms may be operative, but their respective contributions remain to be determined $[5,25]$.

Increased GI permeability is associated with a number of inflammatory conditions of the GI tract $[16,17,19]$. However, we found no relationship between GI permeability and the feeding outcomes. Small intestinal permeability increases and then decreases with age in the preterm infant [8]. It is possible that these developmental changes in small intestinal permeability may obscure any relationship with feeding intolerance. To our knowledge, whole bowel and colonic permeability have not been measured previously in preterm infants.
Calprotectin is a calcium-binding protein found in neutrophils, monocytes, and macrophages, which resists degradation in the GI tract, is excreted in feces, and is a noninvasive measure of GI inflammation [28-30]. However, our data demonstrated no relationship between fecal calprotectin concentration and the feeding outcomes. It is possible that the known elevated levels of fecal calprotectin in this population masked our ability to identify a relationship [20]. The values we report are similar to those reported for term infants [31].

Increased GRV is believed to be related, in part, to delayed gastric emptying. Thus, we anticipated that the feeding outcomes would correlate with gastric emptying. Carlos et al. [32], using ultrasound, suggested a relationship between the time for maximal antral distention and half antral clearance between feeding intolerant and tolerant infants as defined by a GRV $>50 \%$. These ultrasound data appear to be in conflict with those from Berseth et al. [33] who, using manometry, demonstrated that gastric antral motor activity is similar between term and preterm infants. Our results are not directly comparable with those of Carlos et al. [32] because of the different methodologies and the different ages when the infants were studied. We have shown previously in preterm infants that the gastric emptying rate is correlated positively to birth gestational age but not to postnatal age [11]. Although the mean half emptying times we observed may suggest that the stomach would not be empty by the time of the next feeding (i.e. every $3 \mathrm{~h}$ ), gastric emptying is nonlinear with the rate increasing with time [34]. Thus, it is possible that the stomach could be almost empty by $3 \mathrm{~h}$. On the other hand, a small delay would explain why some residual would be in the stomach prior to the next feeding and, therefore, may still be 'physiologic'. This rate of emptying is comparable to that seen in our earlier smaller study examining the dietary factors controlling gastric emptying [11].

Abdominal distention could also result from poor motor function beyond the stomach (i.e., the small intestine). Studies demonstrate that the motor function of the small intestine is underdeveloped in preterm infants [35]. Although stooling pattern would seem to provide some insight into GI motor activity, feeding or lack thereof alone would influence stooling frequency. Thus, it is not possible to use this as a predictor of feeding outcome.

Some limitations to our study should be noted. In some cases, we were not able to carry out the GI tests well in advance of when the infants received full gavage feedings. Thus, their ability to predict full gavage feedings may have been compromised. Similarly, it is possible that 
if the GI tests could have been done with more frequency, we would have observed a closer relationship with feeding outcome. However, these critiques do not apply to the results of the GRV and abdominal distention data as these were recorded from the first day of feeding. That lactase activity and GI permeability are still undergoing large changes beyond 28 days of age in preterm infants could imply that these tests might be related to feeding intolerance as reflected by feeding volume $[5,8]$. However, this was not the case.

It should be noted that our results apply to the GRV thresholds that were tested. It is possible that different results would accrue using different GRV thresholds. However, our finding that there was not a relationship between GRV and feeding intolerance finds some substantiation in the study by Cobb et al. [36] who noted a large degree of overlap in GRV between infants who did/ did not develop necrotizing enterocolitis.

We speculate that delays in attaining full feedings are probably related to multiple factors (such as those we tested) acting simultaneously. In addition to the factors we tested, other components of the GI tract known to be im- mature may also contribute (e.g. immature small and/or large bowel motility, low lipase activity, an unstable intestinal microbiome). Although we attempted to test as many factors as frequently as we could, testing them all simultaneously would be too much burden for a (very) low birth weight infant, particularly since testing longitudinally as soon after birth as possible would be optimal.

In summary, GRV, abdominal distention and, except for lactase activity, GI tests did not show correlations with feeding outcomes. Studies are needed in which infants are randomized to different GRV management protocols to determine if GRV can be used to direct feeding management and affect feeding outcome.

\section{Acknowledgements}

The authors wish to thank Raheela Khan for her assistance.

This research was supported by a grant from the Gerber Foundation, the USDA/ARS under Cooperative Agreement No. 625051000-043, the Daffy's Foundation, and P30-DK56338 which funds the Texas Medical Center Digestive Disease Center.

\section{References}

1 Neu J, Zhang L: Feeding intolerance in verylow-birthweight infants: what is it and what can we do about it? Acta Paediatr Suppl 2005; 94:93-99.

-2 Mihatsch WA, von SP, Fahnenstich H, Dehne N, Ebbecke H, Plath C, von Stockhausen HB, Muche R, Franz A, Pohlandt F: The significance of gastric residuals in the early enteral feeding advancement of extremely low birth weight infants. Pediatrics 2002;109: 457-459.

-3 Jadcherla SR, Kliegman RM: Studies of feeding intolerance in very low birth weight infants: definition and significance. Pediatrics 2002;109:516-517.

4 Berseth CL, Nordyke CK: Manometry can predict feeding readiness in preterm infants. Gastroenterology 1992;103:1523-1528.

-5 Shulman RJ, Schanler RJ, Lau C, Heitkemper $\mathrm{M}, \mathrm{Ou} \mathrm{CN}$, Smith EO: Early feeding, feeding tolerance, and lactase activity in preterm infants. J Pediatr 1998;133:645-649.

-6 Weaver LT, Laker MF, Nelson R: Neonatal intestinal lactase activity. Arch Dis Child 1986;61:896-899.

7 Weaver LT, Laker MF, Nelson R: Intestinal permeability in the newborn. Arch Dis Child 1984;59:236-241
8 Shulman RJ, Schanler RJ, Lau C, Heitkemper M, Ou C-N, Smith EO: Early feeding, antenatal glucocorticoids, and human milk decrease intestinal permeability in preterm infants. Pediatr Res 1998;44:519-523.

$\checkmark 9$ Carroll D, Corfield A, Spicer R, Cairns P: Faecal calprotectin concentrations and diagnosis of necrotising enterocolitis. Lancet 2003;361:210-311.

10 Pozler O, Neumann D, Vorisek V, Bukac J, Bures J, Kokstein Z: Development of gastric emptying in premature infants. Use of the (13)C-octanoic acid breath test. Nutrition 2003;19:593-596.

11 Ramirez A, Wong WW, Shulman RJ: Factors regulating gastric emptying in preterm infants. J Pediatr 2006;149:475-479.

-12 Schanler RJ, Shulman RJ, Lau C, Smith EO, Heitkemper MM: Feeding strategies for premature infants: randomized trial of gastrointestinal priming and tube-feeding method. Pediatrics 1999;103:434-439.

13 Schanler RJ: The low birth weight infant: perinatal nutrition; in Walker WA, Watkins JB, (eds): Nutrition in Pediatrics: Basic Science and Clinical Applications. Hamilton, Decker, 1996, pp 387-407.

-14 Schanler RJ, Shulman RJ, Lau C: Feeding strategies for premature infants: beneficial outcomes of feeding fortified human milk versus preterm formula. Pediatrics 1999;103 $1150-1157$.
15 Moody GJ, Schanler RJ, Lau C, Shulman RJ: Feeding tolerance in premature infants fed fortified human milk. J Pediatr Gastroenterol Nutr 2000;30:408-412.

-16 Shulman RJ, Eakin MN, Czyzewski DI, Jarrett $\mathrm{M}, \mathrm{Ou} \mathrm{CN}$ : Increased gastrointestinal permeability and gut inflammation in children with functional abdominal pain and irritable bowel syndrome. J Pediatr 2008;153: 646-650.

17 Noone C, Menzies IS, Banatvala JE, Scopes JW: Intestinal permeability and lactose hydrolysis in human rotaviral gastroenteritis assessed simultaneously by non-invasive differential sugar permeation. Eur J Clin Invest 1986;16:217-225.

18 Meddings JB, Gibbons 1: Discrimination of site-specific alterations in gastrointestinal permeability in the rat. Gastroenterology 1998;114:83-92.

19 Teshima CW, Meddings JB: The measurement and clinical significance of intestinal permeability. Curr Gastroenterol Rep 2008; 10:443-449.

20 Yang Q, Smith PB, Goldberg RN, Cotten CM: Dynamic change of fecal calprotectin in very low birth weight infants during the first month of life. Neonatology 2008;94:267-271. 
-21 Veereman-Wauters G, Ghoos Y, van der Schoor S, Maes B, Hebbalkar N, Devlieger H, Eggermont E: The 13C-octanoic acid breath test: a noninvasive technique to assess gastric emptying in preterm infants. J Pediatr Gastroenterol Nutr 1996;23:111-117.

-22 Barnett C, Snel A, Omari T, Davidson G, Haslam R, Butler R: Reproducibility of the ${ }^{13} \mathrm{C}$-octanoic acid breath test for assessment of gastric emptying in healthy preterm infants. J Pediatr Gastroenterol Nutr 1999;29: 26-30.

23 McClave SA, Snider HL: Clinical use of gastric residual volumes as a monitor for patients on enteral tube feeding. JPEN J Parenter Enteral Nutr 2002;26:S43-S48.

24 Henning SJ, Rubin DC, Shulman RJ: Ontogeny of the intestinal mucosa; in Johnson LR, (ed): Physiology of the Gastrointestinal Tract. New York, Raven Press, 1994, pp 571610.
25 Shulman RJ, Wong WW, Smith EO: Influence of changes in lactase activity and smallintestinal mucosal growth on lactose digestion and absorption in preterm infants. Am J Clin Nutr 2005;81:472-479.

26 Griffin MP, Hansen JW: Can the elimination of lactose from formula improve feeding tolerance in premature infants? J Pediatr 1999; 135:587-592.

27 Erasmus HD, Ludwig-Auser HM, Paterson PG, Sun D, Sankaran K: Enhanced weight gain in preterm infants receiving lactasetreated feeds: a randomized, double-blind, controlled trial. J Pediatr 2002;141:532-537.

28 Roseth AG, Fagerhol MK, Aadland E, Schjonsby H: Assessment of the neutrophil dominating protein calprotectin in feces. A methodologic study. Scand J Gastroenterol 1992;27:793-798.

29 Aadland E, Fagerhol MK: Faecal calprotectin: a marker of inflammation throughout the intestinal tract. Eur J Gastroenterol Hepatol 2002;14:823-825.

-30 Bunn SK, Bisset WM, Main MJ, Gray ES, Olson S, Golden BE: Fecal calprotectin: validation as a noninvasive measure of bowe inflammation in childhood inflammatory bowel disease. J Pediatr Gastroenterol Nutr 2001;33:14-22.
31 Campeotto F, Butel MJ, Kalach N, Derrieux S, Aubert-Jacquin C, Barbot L, Francoual C, Dupont C, Kapel N: High faecal calprotectin concentrations in newborn infants. Arch Dis Child Fetal Neonatal Ed 2004;89:F353-F355.

\32 Carlos MA, Babyn PS, Marcon MA, Moore AM: Changes in gastric emptying in early postnatal life. J Pediatr 1997;130:931-937.

>33 Berseth CL, Ittmann PI: Antral and duodenal motor responses to duodenal feeding in preterm and term infants. J Pediatr Gastroenterol Nutr 1992;14:182-186.

-34 Parkman HP, Jones MP: Tests of gastric neuromuscular function. Gastroenterology 2009;136:1526-1543.

35 Baker J, Berseth CL: Postnatal change in inhibitory regulation of intestinal motor activity in human and canine neonates. Pediatr Res 1995;38:133-139.

36 Cobb BA, Carlo WA, Ambalavanan N: Gastric residuals and their relationship to necrotizing enterocolitis in very low birth weight infants. Pediatrics 2004;113:50-53. 